\title{
Constitucionalización del derecho internacional de las inversiones: los casos de la expropiación indirecta y el trato justo y equitativo*
}

\section{Constitutionalization of international investment law: Indirect expropriation cases, fair and equitable treatment}

\author{
CÉSAR HIGA** \\ VÍCTOR SACO***
}

Resumen: Este trabajo tiene como objeto explorar el impacto que tienen las normas del derecho internacional de las inversiones, en específico aquellas de los capítulos de inversiones de los Tratados de Libre Comercio celebrados por el Perú, en el derecho constitucional económico. En concreto, se pretende demostrar lo siguiente: (i) el derecho internacional de las inversiones es parte del Ordenamiento Jurídico del Perú; (ii) las disposiciones de este derecho son obligatorias y deben aplicarse a nivel interno, y (iii) este derecho debe interpretarse e implementarse de manera coherente con el resto del ordenamiento interno y con las obligaciones internacionales del Perú. Esta interpretación concordada del derecho de inversiones y la Constitución económica tendrá un impacto positivo en la racionalización de la actuación de los órganos estatales, evitando arbitrariedades cuando sus medidas puedan afectar a un inversionista. De esta manera mejorará el clima de inversiones, el cual es un elemento necesario para lograr el desarrollo sostenible del país.

Palabrasclave: derechointernacional de lasinversiones-constitucionalizacióntrato justo y equitativo - expropiación indirecta - rule of law - derecho internacional de los derechos humanos - coherencia - interpretación coherente - clima de inversión

Abstract: The purpose of this paper is to explore the impact of international investment law rules in the Economic Constitutional Law, especially those included in investment chapters of Peruvian's Free Trade Treaties. In particular, it is expected to demonstrate the following (i) International Investment Law is part of Peruvian Legal System; (ii) provisions of these laws are mandatory and should be applied domestically; and (iii) interpretation and implementation of this legal right should be executed consistently with domestic legal system and Peruvian international obligations. This agreed Interpretation between Investment Law and Economic Constitution will have a positive effect in rationalization of public entities actions avoiding abuses and maltreatment

* Los autores quieren agradecer a los profesores Elvira Méndez y Manuel Monteagudo por sus invalorables comentarios al borrador de este documento.

** Magíster en Teoría de la Argumentación. Profesor de la Pontificia Universidad Católica del Perú. Correo electrónico: chiga@pucp.edu.pe

*** Magíster en Derecho Internacional y Derecho Europeo. Profesor de la Pontificia Universidad Católica del Perú. Correo electrónico: victor.saco@pucp.edu.pe 
to investors, in order to improve investment climate as a key element for achieving country's sustainable development.

Key words: international investments law - constitutionalization - fair and equitable treatment - indirect expropriation - rule of law - international law of human rights - consistency - consistent interpretation - investment climate

CONTENIDO: I. INTRODUCCIÓN: ASPECTOS PREVIOS.- II. CONSTITUCIONALIZACIÓN DEL DERECHO INTERNACIONAL DE LAS INVERSIONES.III. OBLIGATORIEDAD DEL DERECHO INTERNACIONAL DE LAS INVERSIONES Y EN ESPECIAL DE LAS CLÁUSULAS QUE PROHÍBEN UN TRATO INJUSTO E INEQUITATIVO Y UNA EXPROPIACIÓN INDIRECTA.- III.1. ARGUMENTOS POLÍTICOS: «MONISMO DE FACTO».- III.2. EL OBJETIVO POLÍTICO DEL ESTADO PERUANO EN LA CELEBRACIÓN DE LOS TRATADOS DE INVERSIÓN Y LAS CONSECUENCIAS JURÍDICAS DE ESE OBJETIVO: EL FORTALECIMIENTO DEL RULE OF LAW PERUANO FRENTE A LOS INVERSIONISTAS EXTRANJEROS Y LA IMPORTANCIA DEL MARCO INSTITUCIONAL PARA EL DESARROLLO DE UN PAÍS.- III.3. ARGUMENTOS JURÍDICOS DE LA OBLIGATORIEDAD INTERNA DEL DERECHO INTERNACIONAL DE LAS INVERSIONES.- III.3.1. IGUALDAD DE DERECHOS ENTRE LOS INVERSIONISTAS NACIONALES Y LOS EXTRANJEROS.III.3.2. DERECHOS RECONOCIDOS A LOS INVERSIONISTAS EXTRANJEROS COMO DERECHOS HUMANOS.- III.4. LA EXPROPIACIÓN INDIRECTA Y EL TRATO JUSTO Y EQUITATIVO COMO NORMAS DEL DERECHO INTERNACIONAL DE LAS INVERSIONES CONSTITUCIONALIZADAS OBLIGATORIAS.- III.4.1. EXPROPIACIÓN INDIRECTA.- III.4.2. TRATO JUSTO Y EQUITATIVO.- IV. LA NECESIDAD DE UNA INTERPRETACIÓN COHERENTE DEL DERECHO INTERNACIONAL DE LAS INVERSIONES CON LA CONSTITUCIÓN PERUANA.- V. CONCLUSIÓN.

I. INTRODUCCIÓN: ASPECTOS PREVIOS

El derecho internacional tiene un impacto en el derecho interno, dado que este último debe adaptarse al primero para no violarlo. Sin embargo, el derecho internacional reconoce que el Estado tiene márgenes de actuación para incorporar sus obligaciones internacionales en su ordenamiento. Por ello, ambos ordenamientos jurídicos tienen que ajustarse mutuamente para evitar contradicciones entre ambos o el rechazo de uno al otro. El punto de encuentro de esta adaptación y coordinación se encontrará en la Constitución, que es la base de todo el derecho interno peruano. La interpretación será el mecanismo de coordinación entre ambos ordenamientos que se estudiará en este trabajo. La forma como se interprete la Constitución para adaptar e incorporar el derecho internacional de inversiones en nuestro ordenamiento tendrá impacto, luego, en el derecho administrativo. 
Entre todas las fuentes de derecho relacionadas con los inversionistas extranjeros, se ha optado por los Capítulos de Inversión de los Tratados de Libre Comercio porque sus normas recogen las más recientes interpretaciones que los tribunales internacionales han hecho sobre los derechos de los inversionistas (en específico, una lectura más restringida de los conceptos de expropiación indirecta y trato justo y equitativo, estándares que fueran criticados en tratados previos por ser muy amplios). A manera de ejemplo, utilizaremos las normas del Acuerdo de Promoción Comercial entre Estados Unidos y Perú (en adelante, TLC). En ese sentido, se analizará cuál será el impacto de las cláusulas sobre expropiación y trato justo y equitativo en el ordenamiento jurídico peruano.

El derecho administrativo interesa debido a que regula la relación del Estado con los ciudadanos y, especialmente, con los inversionistas nacionales o extranjeros. Además, las normas que protegen a los inversionistas están íntimamente relacionadas con las formas como el Estado regula determinadas actividades económicas o afecta la propiedad privada; por ejemplo, cuando expropia terrenos para realizar una obra pública, cuando entrega una concesión o cuando regula el uso de recursos naturales.

La tesis que intentaremos probar en este trabajo es que, al ser la coherencia del sistema de reglas y principios un valor fundamental en cualquier ordenamiento jurídico - y, por tanto, también del peruano-, las normas sobre protección del inversionista extranjero y la Constitución se deben ajustar mutuamente de manera tal que no existan contradicciones entre ambos órdenes'. En efecto, el ordenamiento jurídico no puede aceptar que existan normas que garanticen, por ejemplo, la igualdad, pero que, por otro lado, existan otras que permitan un trato desigual entre las personas a pesar de encontrarse en la misma situación. Ante este tipo de situaciones se debe buscar interpretar, en la medida de lo posible, que las normas tengan una coherencia entre sí, dado que forman parte de un mismo ordenamiento jurídico y están regidas por los mismos principios y valores. Si se considera que el derecho peruano es un todo coherente, entonces se deben buscar mecanismos que garanticen esa coherencia2.

Para probar esta tesis, se analizará primero la relación entre el derecho internacional y el derecho interno, demostrando que ambas ramas del derecho son igualmente obligatorias y aplicables en el ámbito interno.

1 Al respecto, ver la obra de DwORKIN, Ronald. Law's Empire. Cambridge, Massachusetts. The Belknap Press of Harvard University Press , p. 226. En esta obra, el autor da a entender que la labor de los operadores jurídicos sería analizar la práctica jurídica a efectos de darle una interpretación comprehensiva a esa práctica.

2 De acuerdo con el Diccionario de la Lengua Española (REAL ACADEMIA ESPAÑola. Vigésima segunda edición. Madrid: Espasa Calpe, 2001), coherencia, en su segunda acepción: «Actitud lógica y consecuente con una posición anterior». http://lema.rae.es/drae/?val=coherencia (Consulta: 13 de mayo de 2013).

CONSTITUCIO-

NALIZACIÓN DEL

DERECHO

INTERNACIONAL DE

LAS INVERSIONES:

LOS CASOS DE LA

EXPROPIACIÓN

INDIRECTAYEL

TRATO JUSTOY

EQUITATIVO

CONSTITUTIO-

NALIZATION OF

INTERNATIONAL

INVESTMENT LAW:

INDIRECT

EXPROPRIATION

CASES, FAIR

AND EQUITABLE

TREATMENT 
En un segundo momento, se estudiarán los derechos de los inversionistas a no ser expropiados indirectamente y a ser tratados de manera justa y equitativa y su impacto en el derecho interno. Finalmente, se propondrán algunas reformas con el fin de sacar mejor provecho al derecho internacional de las inversiones.

Es preciso enfatizar que el enfoque de coherencia en este trabajo se aplica en el ordenamiento jurídico interno. Si se tomara como punto de partida el derecho internacional, la coherencia sería leída como una adaptación del derecho interno al derecho internacional, por lo tanto susceptible a una crítica de subordinación del primero frente al segundo. Contra esto último se podría argumentar que tal subordinación no existe, pues el derecho internacional convencional es fruto de las negociaciones libres de los Estados, que plasman sus normas e intereses internos en el acuerdo internacional. Igualmente, es preciso recordar que, fácticamente, el derecho internacional se aplica a partir de los actos de los Estados, y la gran mayoría de este actuar se produce como resultado de la aplicación del derecho interno. Los autores somos conscientes del debate por lograr que la coherencia sea de una vía de doble sentido ${ }^{3}$, sin embargo, para propósitos de la línea argumentativa del artículo, profundizar en la temática no generaría una solución diferente de la tesis expuesta en estas líneas.

\section{CONSTITUCIONALIZACIÓN DEL DERECHO INTERNACIONAL DE LAS INVERSIONES}

El derecho internacional de las inversiones ${ }^{4}$ es parte del derecho interno peruano. El principal argumento en el que se basa esta afirmación se encuentra en la Constitución, que reconoce en su artículo 53 que los tratados ratificados y en vigor forman parte del derecho nacional. Esta postura es conocida por la doctrina como «monismo», por considerar que el derecho internacional y el derecho interno forman parte de un solo ordenamiento jurídico 5 .

3 Esta idea se encuentra en COTTIER, Thomas. Multilayered Governance, Pluralism and Moral Conflict. Working Paper 2008/23, December. http://phase1.nccr-trade.org/images/stories/publications/IP1/rev. Multilayered_Governance_Cottier_final_\%20draft_1208.pdf. Citado por CORVAGLIA, Maria Anna. The Contribution of Public Procurement to Coherence of the Multilayered Governance in Implementing Labor Standards. 2012. http://www.wti.org/fileadmin/user_upload/nccr-trade.ch/wp1/Maria_Anna_ Corvaglia_IPPC_Conference_WTI08.06_finale.pdf.

4 Entendemos por derecho internacional de las inversiones al conjunto de normas que regulan las inversiones extranjeras. Si bien la mayoría de estas normas internacionales derivan de tratados bilaterales, esto no afecta su fuente internacional.

5 Sobre el monismo, ARANGIO-RUIZ, Gaetano («International and Interdividual Law». En Janne NiJMAN y André NOLLKAEMPER [eds.]. New perspectives on the divide between National and International Law. Nueva York: OUP, 2007, pp. 15-51) considera lo siguiente: «The prima facie impression is thus one of coexistence of the two sets of norms (or the two sets of legal rights or obligations) within a single normative context addressing itself directly to individuals as well as States. That the coexistence of the two sets of norms does not imply that they belong to one and the same system inevitable appears $[\ldots]$ (p. 16). 
La teoría monista no considera a ambos ordenamientos como compartimientos estancos, donde cada uno establece una regulación propia sobre los derechos y deberes de las personas en ciertas actividades sin que le importe si existen contradicciones entre ambos órdenes. Es cierto que teórica y jurídicamente puede argumentarse que tratamos con dos ramas del derecho distintas ${ }^{6}$; sin embargo, la globalización y la realidad interdependiente de los Estados han hecho que esta teoría tradicional haya cedido. Varias teorías han demostrado esta interdependencia, como el derecho administrativo global ${ }^{7}$ o la teoría del gobierno de múltiples niveles (multilayered governance) ${ }^{8}$.

El impacto de esta unión de ordenamientos jurídicos ha originado que las obligaciones internacionales sean una nueva «fuente de derecho interno» y que la normativa interna, incluso la Constitución, deba ser interpretada de acuerdo con las normas internacionales. Un ejemplo de esto último lo encontramos en la regulación de los derechos humanos: nuestra Constitución tiene una cláusula especial, su artículo tercero 9 , en virtud del cual el número de derechos humanos protegidos por la Constitución no se limita a los listados en sus dos primeros artículos. De esta forma, a los derechos protegidos constitucionalmente se adhieren otros reconocidos por tratados de derechos humanos. Igualmente, su interpretación evoluciona a la luz de los tratados de derechos humanos y la forma como estos acuerdos son interpretados por sus Cortes y órganos, en virtud de la propia Constitución ${ }^{10}$ y el Código Procesal Constitucional ${ }^{11}$. Al igual que el derecho internacional de los derechos humanos, otras normas de derecho internacional que sean vinculantes

6 De acuerdo con GAJA, Giorgio («Dualism a review». En Janne NIJMAN y André NolLKAEMPER [eds.]. Ob. cit., pp. 53ss.): «The main feature of dualism appears to be that international law and municipal laws are viewed as separate legal systems, which may be defined as self-contained, because within each system the only existing rules are those that are part of the system. Rules which are not created within the system may nevertheless be relevant for the system if they are referred to by a rule included in the system".

7 Documentos sobre el derecho administrativo global pueden encontrarse en: «GALhome», online: http://www.iilj.org/gal/

8 Sobre esta teoría, COTTIER, Thomas («Towards a five storey house». En Christian JOERGES y Ernst-Ulrich Petersmann [eds.]. Constitutionalism, Multilevel Trade Governance and International Economic Law. Studies in International Trade Law. Volume 12. Oxford y Portland: Hart Publishing, 2011, pp. 495-53) presenta el ejemplo de cinco capas o pisos de una casa que deben coexistir (p. 497).

9 «Artículo 3.- La enumeración de los derechos establecidos en este capítulo no excluye los demás que la Constitución garantiza, ni otros de naturaleza análoga o que se fundan en la dignidad del hombre, o en los principios de soberanía del pueblo, del Estado democrático de derecho y de la forma republicana de gobierno" (CONGRESo ConstituYente Democrático. Constitución Política del Perú. Lima, 1993).

10 «Disposiciones finales y transitorias. Cuarta. Las normas relativas a los derechos y a las libertades que la Constitución reconoce se interpretan de conformidad con la Declaración Universal de Derechos Humanos y con los tratados y acuerdos internacionales sobre las mismas materias ratificados por el Perú» (Ibíd.).

11 «Artículo V.- Interpretación de los Derechos Constitucionales, Ley 28237.- El contenido y alcances de los derechos constitucionales protegidos por los procesos regulados en el presente Código deben interpretarse de conformidad con la Declaración Universal de Derechos Humanos, los tratados sobre derechos humanos, así como de las decisiones adoptadas por los tribunales internacionales sobre derechos humanos constituidos según tratados de los que el Perú es parte» (CONGRESO DE LA República del Perú. Código Procesal Constitucional. Lima, 2004). 
para el Perú forman parte de su ordenamiento interno, aunque su obligatoriedad no sea desarrollada por normas internas.

\section{OBLIGATORIEDAD DEL DERECHO INTERNACIONAL DE LAS INVERSIONES Y EN ESPECIAL DE LAS CLÁUSULAS QUE PROHIIBEN UN TRATO INJUSTO E INEQUITATIVO Y UNA EXPROPIACIÓN INDIRECTA}

Dos tipos de argumentos pueden esgrimirse para sostener la obligatoriedad del derecho internacional de las inversiones en el derecho interno: argumentos políticos y argumentos jurídicos. Los argumentos jurídicos se adicionan al mencionado en el acápite anterior: el monismo constitucional peruano. A estos se deben añadir los argumentos políticos que expresan los motivos por los que se ratificaron los tratados internacionales y su cumplimiento.

\section{III.1. Argumentos políticos: «monismo de facto»}

El monismo que recoge nuestra Constitución no solo tiene un impacto jurídico: implica también una estrategia política. Por ello, los funcionarios públicos deben hacer una revisión de la normativa interna para encontrar las normas del derecho interno que contradigan los acuerdos internacionales antes de su ratificación, con el fin de modificar el tratado, no ratificarlo o formular reservas. El monismo tiene un impacto en las políticas internas, ya que estas se deben planificar evitando incumplir con lo acordado en el ámbito internacional.

A este monismo de iure se le debe agregar el monismo de facto que se presenta en el derecho internacional actual, especialmente en los Estados que son parte de procesos de integración o miembros de instituciones internacionales que cuentan con órganos de solución de diferencias. El monismo de facto es la situación por la cual los Estados, sean o no monistas, respetan el derecho internacional no solo porque sea obligatorio, sino también para evitar las consecuencias económicas y políticas de incumplir una obligación internacional (p.e. pagar compensaciones o subir sanciones político/económicas). Es claro que el monismo de facto es más evidente en los Estados que no son monistas ${ }^{12}$, también llamados dualistas ${ }^{13}$; sin embargo, el evitar las consecuencias del incumplimiento de las obligaciones internacionales se presenta también en los Estados monistas de manera intrínseca.

12 Por ejemplo, COTTIER, Thomas [«Multilayered Governance, Pluralism, and Moral conflict». Indiana Journal of Global Legal Studies, 16, 2 (Summer 2009), pp. 647- 679] menciona: «Even in monist traditions, the direct effect of international law in domestic law is often denied, and the two spheres end up being artificially separated (citas omitidas)" (p. 648).

13 Ver nota al pie 8 para una definición. 
El monismo de facto tiene impacto en Estados que forman parte de un proceso de integración regional (p.e. Unión Europea, Corte Europea de Derechos Humanos) o de un proceso multilateral que funcione (p.e. Organización Mundial del Comercio), pues estos procesos vienen acompañados de mecanismos de solución de diferencias cuyas sentencias tienen un alto grado de coercibilidad. Sin embargo, el análisis caso por caso será pertinente para determinar el nivel de cumplimiento, tomándose en cuenta aspectos como el poder real de los actores involucrados. Por ejemplo, los casos ante la OMC Estados Unidos vs. Brasil sobre algodón ${ }^{14}$, o Estados Unidos vs. Antigua y Barbuda sobre apuestas ${ }^{15}$ demuestran la capacidad de ciertos Estados — en este caso los Estados Unidos- de resistir o soportar los efectos sancionatorios de las correspondientes resoluciones del Órgano de Solución de controversias de la OMC.

En el derecho internacional de las inversiones, los Estados tienen dos incentivos negativos para no violar las normas internacionales. En primer lugar, las fuertes sumas de dinero que se pueden llegar a pagar a manera de compensación de perderse un arbitraje internacional. Por ejemplo, en el caso CME contra República Checa, este último Estado fue condenado a pagar US\$269,8 millones $^{16}$. En segundo lugar, porque la afectación de los derechos de los inversionistas, corroborada por un tribunal, afecta gravemente la imagen del Estado como un lugar para invertir: el llamado clima de inversión.

En conclusión, el monismo de facto es un complemento al monismo de iure y proporciona efectividad al derecho internacional. Igualmente, el monismo de facto se aplicaría incluso en Estados dualistas o con monismos imperfectos (Estados con normas internas contradictorias a compromisos internacionales). Finalmente, es un mecanismo de coherencia jurídica y política y permite que se eviten arbitrariedades en la actuación del Estado, como se verá más adelante.

14 OMC. United States - Subsidies on Upland Cotton (DS 267). En este caso, frente a la negativa de Estados Unidos de cambiar su legislación interna, se concedió a Brasil el derecho de aplicar medidas de retorsión, las cuales no aplicó, pues negoció una solución al impase directamente con el demandado.

15 OMC. United States - Measures Affecting the Cross-Border Supply of Gambling and Betting Services (DS 285). En este caso se le concedió a Antigua y Barbuda el derecho de aplicar medidas de retorsión contra Estados Unidos por haber violado el Acuerdo General de Comercio de Servicios y no haber cambiado su legislación, que restringía los juegos de azar vía internet afectando a compañías de Antigua y Barbuda, a pesar de la resolución del Órgano de Apelación de la OMC.

16 CME Czech Republic B.V. vs. The Czech Republic, UNCITRAL. Laudo del 14 de marzo de 2003.

CONSTITUCIO-

NALIZACIÓN DEL

DERECHO

INTERNACIONALDE

LAS INVERSIONES:

LOS CASOS DE LA

EXPROPIACIÓN

INDIRECTA Y EL

TRATO JUSTOY

EQUITATIVO

CONSTITUTIO-

NALIZATION OF

INTERNATIONAL

INVESTMENT LAW:

INDIRECT

EXPROPRIATION

CASES, FAIR

AND EQUITABLE

TREATMENT 


\section{III.2. El objetivo político del Estado peruano en la celebración de los tratados de inversión y las consecuencias jurídicas de ese objetivo: el fortalecimiento del Rule of Law peruano frente a los inversionistas extranjeros y la importancia del marco institucional para el desarrollo de un país}

En esta sección queremos mostrar que los tratados de inversión contienen cláusulas orientadas a fortalecer el Rule of Law de un país frente a los inversionistas extranjeros. Esta sería una forma de intervención política del constitucionalismo, en palabras de Petersmann ${ }^{17}$. Uno de los objetivos políticos que se buscaron al momento de celebrar el TLC con los Estados Unidos fue cerrar reformas en el campo económico que se habían realizado en la década de 1990, pero que en el fondo tenían impacto en el Estado de derecho, en especial en el marco institucional peruano.

Para Acemoglu y Robinson, el marco institucional que existe en una sociedad sería la causa fundamental del crecimiento económico de los países ${ }^{18}$ y determina el ritmo de crecimiento entre estos y, por ende, del desarrollo sostenible de un país ${ }^{19}$. Por marco institucional, los autores refieren al conjunto de reglas (formales e informales) que existen en un país respecto del aseguramiento de los derechos de propiedad para las empresas y para los ciudadanos, de la habilidad de estos para elaborar contratos que faciliten las transacciones económicas, las barreras de entrada que enfrentan nuevas empresas para ingresar al mercado y competir, las barreras y costos que los individuos enfrentan para invertir en capital humano, y los incentivos que tienen los políticos para proveer bienes públicos ${ }^{20}$.

17 "The longstanding historical processes of trial and error in designing, applying and improving constitutional have lead to additional 'politic interventions' of constitutionalism, such as (3) the rule of law requirement, (4) respect for human dignity and human rights, (5) democratic self-government, (6) separation of powers and other horizontal and vertical 'check and balances' (such as the subsidiarity requirement), (7) 'social justice' as a precondition for maintaining the needed social consensus over time and, (8) international law as a precondition for the collective supply of international public goods (quotation omitted)». PETERSMANN, Ernst-Ulrich. «Multilevel Trade Governance in the WTO Requires Multilevel Constitutionalism». En Christian JOERGES y Ernst-Ulrich PETERSMANN (eds.). Ob. cit., p. 15.

18 ACEMOGLU, Daron y James ROBINSON. The role of institutions in growth and development. Washington D.C: The International Bank for Reconstruction and Development/The World Bank, 2010. http://siteresources.worldbank.org/EXTPREMNET/Resources/489960-1338997241035/Growth_ Commission_Working_Paper_10_Role_Institutions_Growth_Development.pdf

19 Cabe indicar que el crecimiento económico es condición necesaria, mas no suficiente para el desarrollo sostenible de un país. Para ello, es necesario que el sistema garantice a las personas, entre otros factores, el acceso a una educación y salud de calidad, de manera tal que las personas puedan estar en igualdad de condiciones para competir con otras personas sin importar su nivel económico.

20 ACEMOGLU, Daron. Introduction to economic growth. Nueva Jersey: Princeton University Press, 2009, pp. 781ss. Ver el capítulo 22. 
En un sentido similar, Rodrik ${ }^{21}$ señala que todos los ejemplos de desarrollos exitosos son, en última instancia, el resultado colectivo de decisiones individuales realizadas por emprendedores para arriesgar en nuevas aventuras empresariales y tratar de descubrir nuevos productos. Sin embargo, para lograr que los emprendedores florezcan y desarrollen todas sus potencialidades, es necesario que exista un entorno o marco institucional que les permita apropiarse de los frutos de su esfuerzo, mérito y creatividad. Por ello, agrega Rodrik, la discusión ya no se centra en si las instituciones importan para explicar el desarrollo de un país, dado que ya existe evidencia en ese sentido, sino en cuáles son las instituciones que garantizan lo anterior.

Dentro de las instituciones que incentivarían el desarrollo sostenible de un país se encuentran los siguientes: (i) derechos de propiedad bien definidos; (ii) instituciones regulatorias que busquen que los mercados funcionen eficientemente; (iii) instituciones que garanticen la estabilidad macroeconómica; (iv) instituciones que no dejen desamparados a los sectores sociales que pierden ante cambios en la economía y (v) instituciones que traten de administrar adecuadamente los conflictos que se pueden producir al interior de la sociedad.

Ahora bien, la existencia y estructuración de las reglas económicas que crean los incentivos para el esfuerzo, mérito y creatividad dependen en gran medida del funcionamiento del sistema político y del aparato estatal. Por ello, resulta importante distinguir entre las reglas económicas y las reglas políticas y su interrelación. Las reglas económicas, directamente asociadas con el clima de inversiones, influyen en la decisión de los agentes económicos para invertir en capital físico y humano y la organización de la producción. Sin embargo, como ellas son endógenas (son los mismos individuos los que determinan cómo serán), los distintos actores de la economía querrán reglas de juego que los beneficien, por lo que tratarán de influir en el poder político (el Estado) a efectos de que este cree reglas a su favor.

También pueden darse casos donde los políticos quieran obtener recursos de los agentes económicos para fines privados (financiamiento de campaña, sobornos, etcétera), los cuales se podrían lograr porque tienen el manejo del Estado y sus decisiones serán determinantes en el éxito o fracaso de un emprendimiento empresarial.

En ese sentido, Acemoglu y Robinson ${ }^{22}$ mencionan la importancia de que una determinada élite política o económica no llegue a controlar el sistema político y, por tanto, tenga la capacidad de determinar 
las normas que regirán la vida en sociedad y su aplicación (vía el control de las entidades estatales encargadas de aplicar las reglas). Si ellas logran lo anterior, tratarán de apropiarse de los beneficios del crecimiento económico a través de la aprobación de reglas o medidas estatales que las favorezcan. Por ello resulta clave la existencia de reglas que controlen y racionalicen el ejercicio del poder político y estatal, a efectos de dirigirlo hacia un sistema inclusivo y productivo y no hacia uno extractivo.

Siguiendo esta línea de pensamiento, tal como se señaló al inicio de este trabajo, los tratados de inversión no solo pueden ser vistos como un medio para atraer inversiones foráneas (objetivo económico), sino que también pueden servir para controlar y racionalizar la actuación de los órganos estatales frente a los inversionistas (objetivo político) de manera que se cree un clima de inversiones productivo e inclusivo, el cual será condición necesaria para lograr el crecimiento sostenido de la sociedad.

Este objetivo político adquiere mayor importancia en países con marcos institucionales débiles como es el caso del Perú. En este tipo de países suele ocurrir que el Estado está en función a los intereses privados de los políticos gobernantes, a los intereses de una élite económica con influencia en el gobierno o a la sola voluntad de la autoridad. De este modo, si bien en un inicio pareciera que los interesados en fortalecer el marco institucional a partir de las normas de inversión son solo los inversionistas extranjeros, luego de observar los beneficios de este marco es claro que la sociedad también tiene un legítimo interés.

Cláusulas como la regulación de la expropiación de la propiedad (directa o indirecta) o el trato justo y equitativo se convierten en mecanismos que garantizan que las medidas estatales estén en función de objetivos públicos, sean racionales (medios - fines) y traten de equilibrar el interés de un inversionista con los objetivos públicos, lo cual redundaría en el mejoramiento del clima de inversiones del país, tesis que intentaremos demostrar a continuación. Estas reglas determinarán el marco bajo el cual deberá actuar el aparato estatal si no quiere incurrir en responsabilidad internacional por sus actos.

Cabe señalar que, si bien estas medidas se pueden deducir o construir a partir de los principios y valores contenidos en nuestra Constitución política, ello muchas veces no es respetado internamente porque se enfrenta a los intereses particulares de los políticos, a intereses privados que tienen influencia en el Gobierno o al apresuramiento de los políticos que tratan de responder a las demandas de la opinión pública. Igualmente, al resolverse las disputas fuera del país, el análisis de la medida se podría realizar en un entorno más objetivo, neutral y alejado de las presiones de los intereses políticos y económicos particulares, por cuanto las personas que resolverán la disputa no se verían presionadas ni 
parcializadas por los intereses de algunas de las partes. Esto podría ocurrir en entornos institucionales débiles, como es el caso de países en desarrollo.

Es por ello que, con la aprobación del TLC, se consideraba el cerrar - $\mathrm{O}$, al menos, detener- el retroceso que se había dado en las últimas dos décadas sobre las reformas de apertura y pro mercado que había experimentado el país. En efecto, los tratados de apertura y protección de inversión extranjera garantizaban, como se ha visto, una serie de protecciones a los inversionistas que un nuevo gobierno difícilmente podrá revertir sin provocar la responsabilidad internacional del país.

\section{II.3. Argumentos jurídicos de la obligatoriedad interna del derecho internacional de las inversiones}

Las obligaciones derivadas de los tratadosinternacionales de inversión son parte del derecho interno, y aunque la obligatoriedad de sus disposiciones en derecho interno no se desarrollen específica y expresamente en la Constitución, como en el caso de los derechos humanos, el mismo efecto se logra a partir de dos argumentos que se suman al monismo ya estudiado: (i) la Constitución reconoce la igualdad de derechos entre los inversionistas nacionales y los extranjeros (derivado del también reconocido principio de no discriminación) y (ii) el contenido de varios de los derechos reconocidos a los inversionistas extranjeros está íntimamente ligado a derechos humanos ya reconocidos a cualquier persona - peruana o no- que se encuentre bajo la jurisdicción del gobierno peruano; por ejemplo, la protección del derecho a la propiedad está ligada al derecho al pago de indemnización por expropiación, o el derecho al debido proceso está ligado al trato justo y equitativo.

Estos argumentos permiten un proceso de integración y aplicación del derecho internacional a través de la Constitución, con el efecto de racionalizar la actividad regulatoria del Estado en materia económica y evitar arbitrariedades que perjudiquen el clima de inversiones del Perú, lo cual tendría repercusiones en el desarrollo sostenible del país y, por ende, en el bienestar de la población.

\section{III.3.1. Igualdad de derechos entre los inversionistas nacionales y los extranjeros}

Los inversionistas nacionales y extranjeros tienen los mismos derechos en el Perú (con excepción de la adquisición de terrenos en los $50 \mathrm{~km}$ cercanos a la frontera ${ }^{23}$. Esto de acuerdo con los artículos de la Constitución 63, que reconoce la igualdad de condiciones entre

23 BIT Ecuador Perú. Artículo 3.1 «Cada Parte Contratante, específicamente, concederá a tales inversiones, un trato no menos favorable que el concedido a las inversiones de sus propios inversionistas o a las inversiones de inversionistas de un tercer Estado, considerándose el que sea más favorable para las inversiones de los inversionistas de la otra Parte Contratante».

CONSTITUCIO-

NALIZACIÓN DEL

DERECHO

INTERNACIONAL DE

LAS INVERSIONES:

LOS CASOS DE LA

EXPROPIACIÓN

INDIRECTA Y EL

TRATO JUSTOY

EQUITATIVO

CONSTITUTIO-

NALIZATION OF

INTERNATIONAL

INVESTMENT LAW:

INDIRECT

EXPROPRIATION

CASES, FAIR

AND EQUITABLE

TREATMENT 
inversionistas nacionales y extranjeros; el artículo 2, que reconoce el principio de no discriminación, y el 53, por el cual los tratados son parte del derecho interno.

Igualmente, basados en la jurisprudencia y doctrina sobre derechos humanos ${ }^{24}$, nacionales y extranjeros cuentan con los mismos derechos humanos y se los pueden reclamar al Estado bajo cuya jurisdicción se encuentren. La excepción a esta regla la constituyen algunos derechos políticos y las excepciones al derecho a la propiedad para extranjeros en la frontera.

En virtud de las normas mencionadas al inicio de este acápite, que reconocen la igualdad de derechos de las personas en nuestro ordenamiento jurídico, los derechos otorgados a los extranjeros por la vía de tratados internacionales también deberían ser reconocidos a los nacionales ${ }^{25}$. Los derechos usualmente reconocidos a los inversionistas extranjeros son (i) el recibir una compensación en caso de ser expropiados; (ii) ser tratados de manera justa y equitativa por los organismos del Estado; (iii) que sus inversiones cuenten con seguridad y protecciones plenas; (iv) que se les permita repatriar sus ganancias, y (v) tener acceso a un mecanismo de solución de diferencias internacional (llevar cualquier violación de los derechos anteriores a un tribunal arbitral internacional) ${ }^{26}$, entre otros derechos.

De la revisión profunda de estos derechos, podemos comprobar que su implementación implica un reforzamiento del Estado de derecho en el Estado receptor de inversión y hacer que este sea más atractivo para las inversiones. El reforzamiento del Estado de derecho en nuestro país es, además, un valor de nuestro ordenamiento jurídico que se garantiza a todo ciudadano en nuestro país.

Cabe indicar que ser atractivo para las inversiones no significa que el Estado receptor deba someterse a la voluntad del inversionista en todo aspecto: significa que un Estado, que tiene planteados sus objetivos de desarrollo, permite inversión extranjera en los sectores que contribuirán a ese desarrollo, pero una vez admitidas las inversiones se comprometerá

24 Por ejemplo el punto 6 de la Observación General 15, Comentarios generales adoptados por el Comité de los Derechos Humanos, La situación de los extranjeros con arreglo al Pacto, $27^{\circ}$ período de sesiones, U.N. Doc. HRI/GEN/1/Rev.7 at 159 (1986): «[...] No obstante, una vez que se les permite entrar en el territorio de un Estado Parte, los extranjeros tienen todos los derechos establecidos en el Pacto".

25 Un ejemplo de ello son dos de las disposiciones del Preámbulo de TLC: ACORDAR que, por medio del presente, no se concederá a los inversionistas extranjeros derechos sustantivos más amplios en relación con las protecciones a las inversiones que a los inversionistas nacionales en virtud de la legislación nacional en casos en que, al igual que en los Estados Unidos, las protecciones de los derechos de los inversionistas en virtud de la legislación nacional equivalen o exceden las establecidas en el presente Acuerdo.

RECONOCER que en el Artículo 63 de la Constitución Política del Perú se dispone que «las inversiones nacionales y extranjeras están sujetas a las mismas condiciones».

26 Este derecho será difícil de otorgar al inversor nacional en virtud de los textos de los tratados. 
a tratarlas de buena fe conforme a las reglas de juego, propias de un Estado de derecho. Igualmente, conformarse con las reglas de juego no significa que estas no puedan cambiarse: las normas pueden modificarse con la debida transparencia y siguiendo los procesos debidos.

\section{III.3.2. Derechos reconocidos a los inversionistas extranjeros, como derechos humanos}

Los inversionistas, como personas naturales, nacionales o extranjeras, son a su vez seres humanos que cuentan con derechos fundamentales (ámbito interno) y derechos humanos (ámbito internacional). Es posible que una misma situación fáctica pueda ser caracterizada jurídicamente bajo dos normas. Un ejemplo de ello se da en el ámbito constitucional: la protección contra la expropiación indirecta está protegida por el derecho a la propiedad y el trato justo y equitativo se encuentra protegido por el derecho al debido proceso y el acceso al Poder Judicial (como se explicará más adelante) ${ }^{27}$. Lo importante en estos es lograr que la aplicación de una norma no implique la contradicción de la otra. Estas contradicciones se pueden dar en derecho interno o entre el nivel interno y el internacional ${ }^{28}$, por ello es importante lograr una concordancia de ambos ordenamientos. Es necesario hacer una interpretación coherente del ordenamiento jurídico como uno solo, y ante posibles contradicciones, utilizar técnicas que permitan resolver esas posibles contradicciones.

En el ámbito constitucional, los inversionistas tiene la posibilidad de utilizar las garantías jurisdiccionales internas para proteger sus derechos: la mayoría de tratados que protegen las inversiones extranjeras permiten esta posibilidad a los inversionistas, al igual que la posibilidad de recurrir a un tribunal arbitral internacional (fork in the road). Las ventajas para el Estado de que los inversionistas utilicen el Poder Judicial local es que el juez nacional podrá interpretar toda la normativa involucrada, sea nacional o internacional, y ponderarla (por ejemplo, expropiación y medio ambiente), mientras que en el derecho internacional, dependiendo del tratado y la jurisdicción del tribunal, se corre el riesgo de que este solo pueda aplicar normas sobre inversiones ${ }^{29}$. Igualmente,

27 Es cierto que hay otros derechos, como el acceso a un tribunal arbitral, que solo los poseen los inversionistas extranjeros, aunque podría argumentarse que los mismos derechos pueden ser protegidos mediante el Sistema Interamericano de Derechos Humanos. Sin embargo, estos temas no serán abordados en este artículo, pues requerirían diferentes trabajos.

28 Se ha tomado la idea de COTTIER, Thomas («Multilayered Governance, Pluralism and Moral Conflict». Ob. cit., pp. 10-13). El autor señala que la pluralidad de valores que se pueden expresar luego en normas jurídicas no solo es un problema del derecho internacional, sino que también se puede dar al interior de los países. Incluso señala que muchas de las guerras de la última década han sido guerras internas producto de los conflictos que el sistema político interno no supo procesar. En ese sentido, buscar mecanismos que permitan compatibilizar, uniformizar y solucionar los conflictos que se puedan presentar en las sociedades no solo es un reto del derecho internacional, sino también del derecho interno.

29 Sobre los conflictos normativos que involucran el derecho internacional de las inversiones y otras ramas del derecho internacional, ver por ejemplo VIÑUALES, J.E. The 'Dormant Environment Clause':

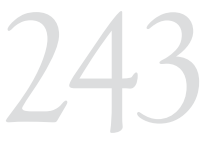

CONSTITUCIO-

NALIZACIÓN DEL

DERECHO

INTERNACIONAL DE

LAS INVERSIONES:

LOS CASOS DE LA

EXPROPIACIÓN

INDIRECTA Y EL

TRATO JUSTOY

EQUITATIVO

CONSTITUTIO-

NALIZATION OF

INTERNATIONAL

INVESTMENT LAW:

INDIRECT

EXPROPRIATION

CASES, FAIR

AND EQUITABLE

TREATMENT 
en el ámbito interno se puede contar con una apelación, posibilidad ausente en el campo internacional (a lo mucho se puede solicitar una anulación en CIADI). Finalmente, en el plano político, el plano interno evita que se rompa la relación inversionista - Estado; normalmente los inversionistas recurren al arbitraje internacional cuando esta relación se ha deteriorado y es irreparable.

Esta limitación de aplicar otras normas de derecho internacional por parte de los tribunales internacionales es meramente aparente, pues de acuerdo con la Convención de Viena sobre el derecho de los tratados, el derecho internacional de las inversiones y los derechos humanos pueden ser interpretados en conjunto, velando por la primacía de los segundos en caso de conflicto ${ }^{30}$. Igualmente, siguiendo el artículo 31 de la Convención de Viena, las otras normas en vigor para la partes pueden ser utilizadas para interpretar una obligación internacional, contando de esta manera con una interpretación evolutiva y coherente ${ }^{31}$. La reciente práctica arbitral en materia de inversiones también ha demostrado que se pueden integrar otras normas internacionales, como las de los derechos humanos, para resolver casos de inversión ${ }^{32}$.

Además de la justicia nacional y los tribunales arbitrales de inversión utilizando los derechos humanos, los inversionistas tienen acceso a los sistemas de protección de los derechos humanos, en específico a la Corte Interamericana de Derechos Humanos, que ya se ha ocupado anteriormente de la protección de derechos humanos relacionados con una inversión (ver, por ejemplo, Baruch Ivcher, aunque sea inversión nacional ${ }^{33}$ ), o a los estándares a seguir para expropiar un terreno (ver Awas Tigni y otros casos sobre comunidades nativas ${ }^{34}$ ).

Sin embargo, es claro que el inversionista recurrirá preferentemente al arbitraje internacional que a la Corte Interamericana de Derechos Humanos, debido a que el procedimiento en el primero es más

Assessing the Impact of Multilateral Environmental Agreements on Foreign Investment Disputes? The Graduate Institute. Centre for International Environmental Studies. Research Paper 9, 2012. http://repository.graduateinstitute.ch/record/12752/files/CIES_RP_09_Vinuales.pdf.

30 Adicionalmente, cuando se producen conflictos entre normas de derecho internacional, la norma por la que se opte como aquella que prevalezca tendrá un impacto en su interpretación en derecho interno. La obra de PAUWELYN, Joost (Conflicts of Norms in Public International Law. How WTO Law relates to other rules of International Law? Cambridge: Cambridge University Press, 2003) es un referente importante en materia de conflictos normativos de derecho internacional.

31 En materia de interpretación de tratados se puede revisar la obra de ORAKHELASHVILI, Alexander. The Interpretation of Acts and Rules in Public International Law. Nueva York: Oxford University Press, 2008.

32 UNCTAD. IIA Monitor No. 2. Selected Recent Developments in IIA Arbitration and Human Rights (UNCTAD/WEB/DIAE/IA/2009/7), 11 jun 2009, pp. 5 y ss. http://unctad.org/en/Docs/webdiaeia20097_en.pdf

33 Sentencia del 6 de febrero de 2001 emitida por la Corte Interamericana de Derechos Humanos (Caso Ivcher Bronstein vs. Perú). http://www.corteidh.or.cr/docs/casos/articulos/seriec_74_esp.pdf (Consulta: 29 de julio de 2013).

34 Sentencia del 31 de agosto de 2001 emitida por la Corte Interamericana de Derechos Humanos. http://www.corteidh.or.cr/docs/casos/articulos/seriec_79_esp.pdf (Consulta: 29 de julio de 2013). 
expeditivo y por la posibilidad de que personas jurídicas puedan ser parte del proceso. Ello a pesar de que estudios han demostrado que en el 51\% de arbitrajes es el Estado el que ha ganado, y cuando los inversionistas han ganado casos las compensaciones otorgadas han sido menores al $40 \%$ de lo demandado ${ }^{35}$.

La posibilidad de que pueda recurrirse a una instancia internacional significa una oportunidad y motivación para el Estado de mejorar su administración de justicia con el fin de posicionarla como una rápida alternativa frente a los reclamos de los inversionistas, permitiendo de esta manera que el clima de inversiones mejore y que los conflictos se resuelvan de manera beneficiosa para todos los actores involucrados. Los beneficios de aplicar el derecho internacional de las inversiones en el ámbito interno se estudian en el siguiente capítulo.

\section{III.4. La expropiación indirecta y el trato justo y equita- tivo como normas del derecho internacional de las inversiones constitucionalizadas obligatorias}

Casi todos los acuerdos de inversión contienen normas que protegen a los inversionistas frente a una posible expropiación o garantizan que sean tratados de manera justa y equitativa; igualmente garantizan que puedan repatriar sus ganancias y que sus personas y bienes gocen de seguridad y protección plena durante el tiempo de la inversión en el Estado receptor, entre otras. De ellas, por motivos metodológicos, solo analizaremos la norma que regula la expropiación indirecta y la que regula el trato justo y equitativo.

La mayoría de estos derechos de los inversionistas ya son protegidos por la legislación interna de los Estados. En el caso peruano, la protección de la propiedad, la protección constitucional de los contratos con los inversionistas extranjeros o la igualdad de estos con los inversionistas nacionales aparecen en la Constitución de 1993 como medidas realizadas destinadas a atraer nuevamente la inversión foránea, luego de la crisis de la década de 1980.

Dentro de las normas del Capítulo de Inversiones del TLC que protegen estos derechos estudiaremos la expropiación indirecta y el trato justo y equitativo.

35 En 2008, 50\% de los casos fueron ganados por el Estado (UNCTAD. IIA Monitor No. 1 (2009) Latest Developments in Investor-State Dispute Settlement [UNCTAD/WEB/DIAE/IA/2009/6], 01 Apr 2009, p. 2. http://unctad.org/en/docs/webdiaeia20096_en.pdf), esta tendencia se ha mantenido: FRANCK, Susan («Investment treaty arbitration: myths, realities and costs». Presentación del 16 de enero de 2013 en el World Trade Institute, 2013.

http://www.wti.org/events-overview/investment-treaty-arbitration-myths-realities-and-costs/). Para datos anteriores a 2007, ver FRANCK, Susan. "The ICSID Effect? Considering Potential Variations in Arbitration Awards». Virginia Journal of International Law, 51, 4 (2011). http://ssrn.com/ abstract $=1842164$. 


\section{III.4.1. Expropiación indirecta}

La protección de la titularidad de una inversión, su explotación económica y la disminución de los riesgos políticos y sociales alrededor de ella son factores claves para que un inversionista decida invertir y llevar adelante sus proyectos en un país, lo cual tendría efectos positivos en el crecimiento económico. Por ejemplo, el Banco Mundial señala que derechos de propiedad seguros vinculan el esfuerzo con la recompensa, asegurando a todas las firmas - grandes o medianas, informales o formales, rurales o urbanas - que serán capaces de apropiarse de los frutos de su inversión. Cuanto más protegidos estén estos derechos, más fuerte será el vínculo entre esfuerzo y recompensa y, así, mayor el incentivo para abrir nuevos negocios, invertir más en los existentes y trabajar más duro ${ }^{36}$.

Sin perjuicio de lo anterior, en la actualidad también se reconoce la vigencia de la potestad expropiatoria del Estado ${ }^{37}$, la cual constituye una de las formas más severas de interferencia que puede sufrir una persona en su derecho de propiedad, dado que mediante la expropiación se priva a una persona de la titularidad de un bien o de su disfrute económico. Ahora bien, dado que esta potestad implica una grave intromisión sobre la propiedad de una persona, la doctrina reconoce que el ejercicio de esta potestad debe someterse a ciertos requisitos que justifiquen su utilización. Por ello, como señalan Dolzer y Schreuer, si bien el derecho internacional reconoce esta potestad estatal, también ha establecido límites y condiciones bajo las cuales se la puede ejercer ${ }^{38}$, los cuales se encuentran incorporados en el TLC.

La expropiación indirecta se regula de acuerdo con el artículo 10.7 y el Anexo 10-B pertinente del Capítulo de Inversiones del TLC. Primero, a pesar de la prohibición general de expropiar, el Estado mantiene el derecho de expropiar una inversión (que puede ser cualquier bien tangible o intangible), siempre y cuando se cumplan los cuatro requisitos determinados por el artículo: (i) por motivos de propósito público; (ii) de una manera no discriminatoria; (iii) mediante el pago pronto, adecuado y efectivo de la indemnización, y (iv) con apego al principio del debido proceso y al artículo 10.5 (que se refiere al nivel mínimo de trato, norma que regula el trato justo y equitativo que revisaremos en adelante) ${ }^{39}$.

36 WORLD BANK. A better investment climate for everyone. World Development Report 2005. Washington D.C.: World Bank y Oxford University Press, 2005, p. 79.

37 Dolzer, Rudolf y Christoph SchreUER. Principles of International Invesment Law. Nueva York: Oxford University Press, 2008, p. 89.

38 lbíd.

39 La redacción de esta cláusula se repite en mucho de los Tratados de Libre Comercio o Inversión celebrados por el Estado peruano con diversos países. Incluso en aquellos casos donde el texto no es el mismo, el sentido de la redacción es similar. Cabe agregar que esta cláusula se repite en muchos Tratados de Inversión celebrados en el ámbito internacional. 
Nos interesa especialmente la expropiación indirecta, que se interpreta a partir del tercer inciso del Anexo $10-\mathrm{B}^{40}$. Este tipo de expropiación se define como una expropiación sin transferencia formal de un título o derecho de dominio, que se produce a partir de un acto o serie de actos que van a tener el efecto de una expropiación clásica, esto es, que el acto realizado dejará sin valor el derecho de propiedad sobre el bien expropiado indirectamente ${ }^{41}$. La determinación de si la actuación del Estado constituye una expropiación indirecta se realiza casuísticamente y el inciso tercero del anexo brinda elementos para llevar a cabo este análisis; en específico:

(i) el impacto económico del acto gubernamental, aunque el hecho de que un acto o una serie de actos de una Parte tenga un efecto adverso sobre el valor económico de una inversión, por sí solo, no establece que una expropiación indirecta haya ocurrido;

(ii) la medida en la cual la acción del gobierno interfiere con expectativas inequívocas y razonables de la inversión, y

(iii) el carácter de la acción gubernamental.

Resalta en el texto del Anexo que los actos destinados y aplicados a proteger todo objetivo «legítimo de bienestar público» no podrán ser considerados como expropiatorios, siempre y cuando no sean discriminatorios. Es decir, los actos regulatorios del Estado para proteger el medio ambiente, por ejemplo, aunque tengan el efecto final de expropiar, no significarán la violación del tratado, salvo circunstancias excepcionales.

La expropiación también está regulada por el derecho interno, siguiendo los artículos 2.16 y $70^{42}$ de la Constitución que desarrollan el derecho de propiedad. Sin embargo, no se regula la expropiación indirecta del TLC en detalle, motivo por el cual consideramos que los criterios aportados por el tratado ayudan a los operadores jurídicos a contar con criterios más objetivos al momento de analizar una expropiación indirecta.

40 El anexo 10-B del Capítulo de Inversiones se indica expresamente que la expropiación puede ser de dos tipos: (i) directa; e, (ii) indirecta. De acuerdo con DOLzER, Rudolf y Christoph SCHREUER. Ob. cit., p. 92, la diferencia gira alrededor de si el título legal del propietario es afectado por la medida en cuestión.

41 Así, la expropiación directa ocurre cuando una inversión es nacionalizada o se transfiere de manera formal el título de la propiedad, mientras que la expropiación indirecta ocurre cuando un acto o una serie de actos de una Parte tienen un efecto equivalente al de una expropiación directa sin la transferencia formal del título o del derecho de dominio. Si bien formalmente no implican que se prive de la titularidad de la propiedad a un inversionista, las medidas realizadas tienen un efecto práctico o económico similar al de una expropiación, porque le impiden disfrutar los beneficios que esperaba obtener con ese bien.

42 Constitución Política del Perú. «Artículo 70.- El derecho de propiedad es inviolable. El Estado lo garantiza. Se ejerce en armonía con el bien común y dentro de los límites de ley. A nadie puede privarse de su propiedad sino, exclusivamente, por causa de seguridad nacional o necesidad pública, declarada por ley, y previo pago en efectivo de indemnización justipreciada que incluya compensación por el eventual perjuicio. Hay acción ante el Poder Judicial para contestar el valor de la propiedad que el Estado haya señalado en el procedimiento expropiatorio». 
Lo mismo sucede con la compensación: la Constitución menciona el pago de un «justiprecio», mientras que el tratado es más específico (el valor justo es el de mercado «que tenga la inversión expropiada inmediatamente antes de que la expropiación se haya llevado a cabo». Este valor debe ser pagado sin demora, ser completamente liquidable y transferible, entre otras disposiciones del artículo 10.7 del TLC).

Regular y especificar la expropiación no implica un pérdida de poder regulatorio para el Estado, pues este cuenta con sus police powers y puede seguir regulando la actividad económica, incluso modificar sus normas, como ha sido reafirmado por la jurisprudencia de los tribunales internacionales en materia de inversión ${ }^{43}$.

Uno de los elementos a tomar en cuenta para determinar si el Estado está permitido de realizar una expropiación es el del trato justo y equitativo que se analiza a continuación y que debe primar durante todo el proceso expropiatorio.

Cabe indicar que la regulación de la expropiación contenida en el literales c) y d) no se encuentra recogida expresamente en la Constitución política peruana ${ }^{44}$. En el ordenamiento jurídico peruano tampoco se encuentra recogida expresamente la expropiación indirecta y la creeping expropiation, motivo por el cual estas disposiciones otorgan un mayor nivel de protección al derecho de propiedad de los inversionistas.

Tal como ha sido señalado, estas cláusulas no están diseñadas solo para proteger el interés de los inversionistas sin que importe el interés público. Estas disposiciones sí permiten que el Estado pueda expropiar el derecho de propiedad de un inversionista, pero bajo ciertos requisitos tales como que: (i) la actuación estatal esté en función al bienestar de la sociedad; (ii) sea racional (una relación de fines - medios) y necesaria (que el medio sea lo menos gravoso posible), y finalmente, (iii) se indemnice al inversionista mediante un pago pronto, adecuado y efectivo por la afectación que sufrirá sobre su propiedad.

Si las autoridades están prevenidas de que tendrán que justificar públicamente cualquier actuación o medida que pueda perjudicar el derecho de propiedad de un inversionista y tendrán que indemnizarlo inmediatamente, será más difícil que la actuación estatal responda al interés privado de los políticos o de una élite económica o su medida no sea racional. En efecto, si el gobierno no puede justificar su actuación, esta resultará inválida y, por tanto, en el ámbito interno se podrá declarar que no tiene efecto dicha actuación, lo cual haría que el gobierno fuese mostrado como arbitrario.

43 Ver entre otros: Methanex Corporation vs. United States of America, NAFTA (UNCITRAL), Laudo del 3 de agosto de 2005, citado por VIÑUALES, J.E. Ob. cit., p. 10. 44 lbíd. 
Por ello, la regulación de la expropiación no solo protege la propiedad de los inversionistas extranjeros, sino que también crea incentivos para controlar y racionalizar la actuación estatal en beneficio de los nacionales. Este hecho tendrá efectos en la creación de un clima de inversiones productivo, porque las reglas que rijan en el mercado estarán dirigidas, de manera técnica, a buscar el bienestar social, lo cual constituiría una mejora del derecho interno administrativo del país.

\section{III.4.2. Trato justo y equitativo}

El capítulo de inversión de los Tratados de Libre Comercio celebrados por el Perú también establece que el Estado debe proporcionar a las inversiones cubiertas un trato acorde con el derecho internacional consuetudinario, incluido «el trato justo y equitativo», así como protección y seguridad plenas ${ }^{45}$. Esta cláusula establece un estándar mínimo de trato que se debe otorgar a un extranjero, así no sea discriminatorio con los nacionales del país ${ }^{46}$, el cual debe ser acorde con el derecho internacional consuetudinario. Así, este es otro derecho que recae en los inversionistas y ha sido regulado de la siguiente manera por el TLC ${ }^{47}$ :

(a) «trato justo y equitativo» incluye la obligación de no denegar justicia en procedimientos criminales, civiles o contencioso-administrativos, de acuerdo con el principio del debido proceso incorporado en los principales sistemas legales del mundo; [...].

Tal como señala la doctrina, esta es, quizás, la cláusula más importante sobre la protección de las inversiones, debido a su carácter de «cláusula de cierre» para la protección de la inversión extranjera en un país. Así, por ejemplo, Dolzer y Schreuer señalan que «el propósito de la cláusula —en los Tratados de Inversión- consiste en llenar los vacíos que podrían ser dejados por los estándares más específicos, a efectos de obtener el nivel de protección deseado por los tratados» ${ }^{48}$. Existe abundante discusión en la doctrina acerca de si el estándar mínimo de trato es distinto del justo y equitativo; sin embargo, se coincide en que,

$45 \mathrm{Al}$ respecto, ver el artículo 10.5 del TLC celebrado con los Estados Unidos.

46 OECD. Fair and Equitable Treatment. International Investment Law: A changing landscape. 2005, p. 100.

47 Este tratamiento es mucho más específico que el realizado por otros tratados que el Perú ha suscrito, donde se menciona por ejemplo: «Cada parte contratante garantizará en todo momento un tratamiento justo y equitativo de las inversiones realizadas por inversiones de la otra parte contratante y no perjudicará la administración, mantenimiento, uso, disfrute o disposición de las mismas a través de medidas arbitrarias o discriminatorias" (Artículo 2.2. de Tratado Bilateral de Inversiones entre Perú y Finlandia) o «Art.3. Cada una de las Partes Contratantes se compromete a asegurar, en su territorio y área marítima, un tratamiento justo y equitativo, conforme a los principios del derecho internacional, a las inversiones de los nacionales y sociedades de la otra parte contratante, de modo que el ejercicio del derecho así reconocido no sea obstaculizado ni de hecho ni de derecho" (Artículo 3 del Tratado Bilateral de Inversiones entre Perú y Francia).

48 DOLZER, Rudolf y Christoph SCHREUER. Ob. cit., p. 122. 
al final, ambas cláusulas se superponen porque muchos de los principios garantizados por uno se pueden derivar del otro ${ }^{49}$.

Como se puede apreciar, esta cláusula está dirigida a evaluar el trato que el Estado le ha otorgado a un inversionista extranjero en el desarrollo de sus actividades económicas en un país. Por eso, siguiendo a Van Harten, los arbitrajes en los tratados de inversión son mecanismos de adjudicación en asuntos de derecho público por dos razones: (i) el sistema es establecido por un acto de soberanía del Estado, y (ii) es predominantemente utilizado para resolver disputas que surgen del ejercicio de la soberanía estatal. Como un sistema de derecho público, analizan la relación que surge entre el Estado y un inversionista a partir de una determinada regulación que le ha sido impuesta a estos últimos ${ }^{50}$.

Hemos revisado anteriormente la opción adoptada en el TLC de tener una definición restringida del trato justo y equitativo, que incluye la obligación de no denegar justicia en procedimientos criminales, civiles o contencioso-administrativos, de acuerdo con el principio del debido proceso incorporado en los principales sistemas legales del mundo. A pesar de ello, es preciso considerar que el trato justo y equitativo ha sido regulado de manera más amplia en otros acuerdos de inversión de los que forma parte el Perú y que, además, está relacionado con el concepto de «estándar mínimo de trato» que debe recibir un inversionista acorde con el derecho internacional consuetudinario, cuya definición es más amplia.

El numeral 1 del artículo 10.5 del TLC establece que cada parte concederá a las inversiones cubiertas un trato acorde con el derecho internacional consuetudinario, incluido el trato justo y equitativo, así como la protección y seguridad plenas. Según el anexo 10-A, el derecho internacional consuetudinario resultará de una práctica general y consistente de los Estados, seguida por ellos en el sentido de una obligación legal. Con respecto al artículo 10.5, el trato mínimo otorgado a los extranjeros por el derecho internacional consuetudinario se refiere a los principios que protegen los derechos económicos e intereses de los extranjeros.

De la revisión de la jurisprudencia arbitral que ha analizado la aplicación de distintos enunciados de trato justo y equitativo ${ }^{51}$, esta cláusula abarcaría los siguientes aspectos ${ }^{52}$ :

a. Transparencia en el proceso de toma de decisión

49 UNCTAD. Fair and Equitable Treatment. UNTACD series on Issues in International Investment Agreement. Nueva York - Ginebra, 1999, p. 1.

50 VAN HARTEN, Gus. Investment Treaty Arbitration and Public Law. Nueva York: Oxford University Press, 2007, p. 45.

51 Ver nota al pie número 11, para algunos ejemplos.

52 Ver, entre otros, los siguientes casos: CMS vs. Argentina; OEPC vs. Ecuador; Metalclad vs. Mexico; Tecmed vs. Mexico; Lauder vs. Czech Republic. Pope \& Talbot v. Canada; GAMI Investment, Inc. vs. Mexico; Saluka vs. Czech Republic. 
b. Predictibilidad

c. Debido proceso formal y sustantivo

d. Estabilidad

e. Protección de las legítimas expectativas del inversionista

f. Libre de coerción y acoso

g. No es sujeto a un tratamiento arbitrario y discriminatorio

h. Proporcionalidad o balance entre el derecho del inversionista y los intereses públicos

Como puede apreciarse, todas estas obligaciones tratan de racionalizar la actuación estatal frente a los derechos de los inversionistas y, de ese modo, evitar la arbitrariedad. Para ello, se crean las siguientes obligaciones:

a. Procedimiento que debe seguir el Estado antes de realizar una determinada actuación;

b. Criterios que el Estado debe tener en cuenta antes de emitir una medida que puede afectar los derechos de un inversionista, y

c. Proporcionalidad o balance entre la medida estatal y los derechos del inversionista.

Según Stephan Schill, el trato justo y equitativo debe ser entendido como el reflejo del principio del Rule of $\mathrm{Law}^{53}$, lo cual consiste en que el gobierno se encuentre limitado por reglas prefijadas y anunciadas previamente que permitirán a los particulares, con relativa certidumbre, prever cómo la autoridad utilizará su poder coercitivo en ciertas circunstancias y, de ese modo, planear sus propios asuntos sobre la base de este conocimiento» ${ }^{54}$.

El concepto del Rule of Law implica, además, que los individuos afectados sean reconocidos como sujetos con derechos a ser tomados en cuenta en el proceso de toma de decisiones públicas, en la búsqueda de un adecuado balance entre los intereses individuales y los intereses públicos, y en el diseño institucional del gobierno, esto es, que debe existir una separación de poderes y una revisión de los actos estatales por un poder judicial independiente ${ }^{55}$. De esta manera, se garantizará un esquema que permita al inversionista extranjero conocer bajo qué

53 SCHILL, Stephan. Fair and Equitable Treatment under Investment Treaties as an Embodiment of the Rule of Law. IILJ Working Paper 2006/6, p. 9.

http://www.iilj.org/publications/documents/2006-6-GAL-Schill-web.pdf

54 HAYEK, Frederich. The Road of Serfdom, p. 54 (1944). Citado por SCHILL, Stephan. Fair and Equitable Treatment under Investment Treaties. Ob. cit. p. 9.

55 SCHILL, Stephan. General Public International Law and International Investment Law - A Research Sketch on Selected Issues, December 2009, p. 15. http://telc.jura.uni-halle.de/sites/default/files/ BeitraegeTWR/Heft\%20105.pdf. Cabe señalar que el Rule of Law no es el único valor político importante en una sociedad, sino que al mismo nivel de este existen otros valores políticos, tales como los derechos humanos, democracia y la economía de mercado, los cuales tratarían de garantizar la

CONSTITUCIO-

NALIZACIÓN DEL

DERECHO

INTERNACIONAL DE

LAS INVERSIONES:

LOS CASOS DE LA

EXPROPIACIÓN

INDIRECTA Y EL

TRATO JUSTOY

EQUITATIVO

CONSTITUTIO-

NALIZATION OF

INTERNATIONAL

INVESTMENT LAW:

INDIRECT

EXPROPRIATION

CASES, FAIR

AND EQUITABLE

TREATMENT 
marco está invirtiendo, planificar su inversión y defenderla ante una medida que pueda perjudicarlo, todo lo cual le permitirá evaluar los riesgos que estaría asumiendo al invertir en el país.

En resumen, este derecho de los inversionistas implica que el Estado permita que el inversionista tenga acceso a la justicia y que esta se aplique respetando el derecho al debido proceso. Estos derechos no solo son reconocidos por la Constitución: además, están protegidos por la Convención Americana sobre Derechos Humanos, la cual ha sido interpretada por la Corte Interamericana de Derechos Humanos en varias oportunidades. Esta Convención se aplica no solo a los nacionales, sino a todas las personas que se encuentran en la jurisdicción del Estado; sin embargo, no a las personas jurídicas.

\section{LA NECESIDAD DE UNA INTERPRETACIÓN COHERENTE DEL DERECHO INTERNACIONAL DE LAS INVERSIONES CON LA CONSTITUCIÓN PERUANA}

Se ha demostrado anteriormente que el derecho internacional de las inversiones, en especial la regulación de la expropiación indirecta y el trato justo y equitativo, son obligatorias en los ámbitos internacional e interno. Igualmente, se han avanzado ideas de los beneficios de implementarlas internamente, a pesar de que constitucionalmente no cuenten con un reconocimiento específico de su obligatoriedad, como en el caso de los derechos humanos. Además, es preciso tomar en cuenta que la jerarquía de los tratados internacionales y sus normas no han sido resueltas por la Constitución, a pesar de los avances realizados por el Tribunal Constitucional. Ahora falta exponer los argumentos por los cuales estas normas, que jurídicamente ya son obligatorias, deben también ser consideradas como tales y, por lo tanto, servir para la interpretación de nuestro ordenamiento jurídico.

Integrar el derecho internacional de la inversiones, o por lo menos las dos normas de este analizadas, se sustenta en el principio de coherencia o el principio de unidad del ordenamiento, que establece que se deben interpretar las disposiciones del ordenamiento como un todo ordenado y sistemático, a partir del cual se organiza el sistema jurídico $0^{56}$. En ese sentido, si se les reconocen ciertos derechos a los inversionistas

cooperación social, la justicia y la dignidad de sus integrantes. Al respecto, ver WALDRON, Jeremy. The Rule of Law and the Measure of Property. The Hamlyn Lectures, July 2011, pp. 6-10. http://papers.ssrn.com/sol3/papers.cfm?abstract_id=1866357

Sin embargo, Waldron señala que no conviene diferenciarlos conceptualmente a efectos de que en caso haya conflicto entre ellos, la discusión sea más ordenada y las consecuencias de preferir, en una determinada situación, un valor sobre el otro.

$56 \mathrm{Al}$ respecto, ver el fundamento 12 de la sentencia del Tribunal Constitucional recaída en el expediente 5854-2005-PA/TC. http://tc.gob.pe/jurisprudencia/2005/05854-2005-AA.html (Consulta: 26 de julio de 2013). 
extranjeros, entonces esos mismos derechos deben ser extensivos a todos los inversionistas nacionales por el principio de igualdad.

A lo anterior debe agregarse que, si el Poder Ejecutivo y el Congreso de la República han negociado, adoptado, firmado y ratificado un tratado que establece derechos y obligaciones que serán respetados por las partes, se entiende que estos órganos públicos aceptan que dichas disposiciones jurídicas no solo serán respetadas para los extranjeros, sino también para los nacionales por una cuestión de consistencia en el comportamiento de los órganos públicos. Ello porque las prácticas jurídicas de los actores públicos deben ser interpretadas como un todo coherente, y no como prácticas aisladas o incluso arbitrarias. Estas prácticas se enmarcan dentro de un sistema jurídico fundado en valores que guían o limitan, según sea el caso, la conducta de los integrantes de la comunidad.

Una idea que se puede extraer de nuestro argumento es que los jueces ${ }^{57}$ deben estar atentos a cuáles son los sentidos interpretativos que darán a las cláusulas sobre trato justo y equitativo y expropiaciones los tribunales arbitrales internacionales a los cuales el Estado peruano está sujeto. Ello porque esa jurisprudencia debe servir como punto de partida para interpretar las disposiciones constitucionales que regulan, entre otros, el derecho de propiedad, expropiación, debido proceso, la discrecionalidad y el poder de policía del Estado. De esa manera, se garantizará la unidad del derecho en el país, lo cual garantizaría que todas las personas sean tratadas de la misma manera por el Estado peruano.

Tal como ha sido señalado, la interpretación de las cláusulas sobre expropiaciones y trato justo y equitativo por los tribunales arbitrales internacionales se ha ido orientando a fortalecer el Estado de derecho de los países. El seguimiento de los criterios mínimos esbozados en la jurisprudencia internacional tiene un impacto positivo en el fortalecimiento del marco institucional del país, que permitirá a su vez crear condiciones para crear un sistema económico que permita el desarrollo sostenible del país.

Consideramos que esta línea interpretativa es la mejor interpretación posible que se puede realizar entre los tratados de inversión suscritos por el Estado peruano y la Constitución peruana, a efectos de garantizar la unidad del derecho peruano. Ello hará cada vez más compleja la labor de los intérpretes jurídicos, pero hará que el derecho peruano sea más dinámico y responda de mejor manera a los desafíos que la globalización y la economía impondrán al país.

Cabe señalar que se han advertido algunos peligros para la aplicabilidad de estas normas internacionales en el ámbito interno. Así, por ejemplo,

\section{NALIZACIÓN DEL}

CONSTITUCIO-

DERECHO

INTERNACIONALDE

LAS INVERSIONES:

LOS CASOS DE LA

EXPROPIACIÓN

INDIRECTA Y EL

TRATO JUSTOY

EQUITATIVO

CONSTITUTIO-

NALIZATION OF

INTERNATIONAL

INVESTMENT LAW:

INDIRECT

EXPROPRIATION

CASES, FAIR

AND EQUITABLE

TREATMENT 
se considera que las normas consuetudinarias del derecho internacional de las inversiones son muy vagas. Ello es cierto: siempre es difícil probar una costumbre; sin embargo, en el caso que se plantea en este trabajo, se ha demostrado que las normas del TLC son mucho más específicas que la norma constitucional existente.

Igualmente, se ha mencionado el hecho de que los tribunales arbitrales pueden y han tenido interpretaciones contradictorias del trato justo y equitativo y la expropiación indirecta ${ }^{58}$; sin embargo, los parámetros del TLC en estas normas son más restrictivos que las normas analizadas por otros tribunales, pero es importante que los tribunales nacionales tomen en cuenta este debate a efectos de comparar las decisiones de los tribunales arbitrales, el contexto en el cual se dieron y su evolución en el tiempo, para darle una interpretación coherente a la jurisprudencia. Para Schill, el método para conocer cómo serán esas reglas previas que permitirán a los inversionistas conocer cómo actuará el Estado en una determinada circunstancia se obtendrá a partir del análisis comparado de los principios adoptados por los sistemas jurídicos de los Estados occidentales. Ello permitirá descubrir y sistematizar aquellas reglas de juego mínimas que los Estados deben garantizar a los inversionistas para crear un clima de inversión que permita el desarrollo económico de sus sociedades, que es el objetivo último que buscan los países al celebrar los tratados de inversión ${ }^{5}$.

Finalmente, se ha mencionado que el derecho internacional de las inversiones busca colocar al inversionista en una mejor posición que el empresario nacional. No estamos de acuerdo con esta afirmación, no solo porque expresamente la Constitución y el Preámbulo del TLC reconocen la igualdad de derechos de inversionistas nacionales y extranjeros, sino también porque no sería sostenible en el tiempo: si los extranjeros tuvieran «mejores» compensaciones que los nacionales frente a una expropiación, los nacionales, al saber que serían expropiados, podrían vender sus derechos a los extranjeros por un precio menor que la «compensación extranjera», pero mayor a la «compensación nacional», o se asociarían a inversionistas extranjeros a efectos de proteger sus inversiones. Es, sin embargo, positivo considerar estos peligros, a efectos de que los hacedores de políticas públicas y los jueces los tengan en cuenta al momento de tomar sus decisiones ${ }^{60}$.

58 Por ejemplo, los casos CME Czech Republic B.V. vs. The Czech Republic y Ronald Lauder vs. Czech Republic, Laudo Final del 3 de setiembre de 2001, se referían a los mismo hechos, uno fue presentado por la empresa y otra por el accionista mayoritario. El primer caso terminó en una reparación por daños por casi US $\$ 270$ millones, el segundo no fue admitido.

59 ScHILL, Stephan. Ob. cit., Fair and Equitable Treatment under Investment Treaties, pp. 29 y ss.

60 Los autores agradecen a Manuel Monteagudo por señalar los mencionados problemas de la tesis de este documento. 
Para terminar, debidoa que el Estado peruano se ha comprometidoa seguir esas reglas de trato mínimas que se deben garantizar a los inversionistas extranjeros para el desarrollo de sus actividades económicas, el Estado debe también respetar ese trato mínimo a los inversionistas nacionales, lo cual presionará para la creación de un entorno institucional productivo e inclusivo que redunde en beneficio del bienestar de la sociedad peruana. Ello también contribuirá a la disminución de la percepción del riesgo que se tiene sobre nuestro país, lo cual hará que los inversionistas se vean más incentivados en invertir en el Perú, o realizar inversiones de largo plazo y a tasas de retorno más bajas. Esto hará que la economía funcione de manera más eficiente.

\section{CONCLUSIÓN}

Como puede apreciarse a lo largo del trabajo, los tratados en materia de inversiones y la Constitución se tienen que adaptar y coordinar recíprocamente, a efectos de que ambos órdenes se integren en un solo ordenamiento coherente. Desde ese punto de vista, los derechos y obligaciones reconocidos a los inversionistas extranjeros también tienen que ser reconocidos a los inversionistas nacionales en virtud al principio de coherencia o de unidad que debe existir en todo ordenamiento jurídico.

En efecto, si nuestra Constitución política reconoce el trato igualitario entre los inversionistas nacionales y extranjeros, basado en el principio de igualdad, entonces todo trato beneficioso que se otorga a un inversionista extranjero también se les debe reconocer a los nacionales. Asimismo, si el Poder Ejecutivo y el Congreso de la República han negociado, adoptado, firmado y ratificado un tratado internacional donde reconocen ciertos derechos a extranjeros en nombre del Estado peruano y establecen cuáles deben ser las condiciones que deben seguir al regular una actividad o expropiar un bien, entonces estos órganos públicos deben tener en cuenta esas mismas reglas cuando regulen las actividades de sus nacionales. La decisión política de asumir y cumplir esos compromisos internacionales no solo debe ser respetada frente a los extranjeros, sino también frente a los nacionales, si es que nos tomamos en serio de que el derecho es uno solo tanto para nacionales como para extranjeros.

Estas reglas fortalecerán el Estado de derecho interno porque establecen una serie de condiciones y requisitos que debe seguir el Estado en caso decida expropiar o regular una actividad que pueda tener un impacto económico significativo en los inversionistas. Entre los principios a tener en cuenta se encuentran, entre otros, los de transparencia, predictibilidad, legítima expectativa, debido proceso, razonabilidad y proporcionalidad. 
Para determinar el contenido de estos principios y su aplicación a casos concretos, resultará importante que la autoridad pública y los jueces realicen un trabajo de sistematización, análisis y evaluación de la jurisprudencia de los tribunales a los cuales se encuentra sometido el Estado en virtud de los tratados de inversión celebrados. Los criterios desarrollados en esta jurisprudencia deberán tomarse en cuenta al momento de interpretar nuestra Constitución. De esta manera, la labor interpretativa de nuestra constitución no solo se debe nutrir de criterios internos sino también externos, que podrían ser más objetivos, independientes y estar al tanto del trato internacional mínimo que debe recibir todo inversionista. Esta práctica interpretativa, consideramos, tendrá un impacto positivo en el fortalecimiento de nuestro marco institucional nacional. 